\title{
Un Niño, un retrato de la miniatura ${ }^{1}$
}

\section{A Child, a portrait of the miniature}

\author{
Amparo Reyes Velázquez \\ Universidad de Quintana Roo (MÉXICO) \\ CE: amprey@uqroo.edu.mx ID ORCID: 0000-0002-3804-5189
}

DOI: $10.32870 /$ sincronia.axxiii.n76.19b19

Esta obra está bajo una Licencia Creative Commons Atribución-NoComercial 4.0 Internacional

Recibido: $27 / 02 / 2019$

Revisado: 07/03/2019

Aprobado: 10/04/2019

\section{RESUMEN}

En el universo textual de Un Niño, Juan Bosch esboza, bajo la dialéctica de la soledad, el arquetipo de la miniatura.

En Un Niño, la miseria inmoviliza y margina a estos pobres seres desdichados. Inermes, que bajo la nostalgia de un rincón, les depara un oscuro destino. En el cuento, la condición deshumana del niño, no es más que "el gran vacío de la eternidad" como anulación de la individualidad.

Juan Bosch, en un escenario adverso, retrata la miniatura del ser de honda sensibilidad humana como desgarrado dramatismo.

Palabras clave: Narrativa. Fenomenología. Miniatura. Soledad. Miseria.

\section{Abstract:}

In the textual universe of Un Niño, Juan Bosch sketches, under the dialectic of solitude, the archetype of the miniature.

\footnotetext{
${ }^{1}$ El presente estudio forma parte de mi investigación doctoral.
} 
In Un Niño, the misery immobilizes and marginalizes these poor unhappy human beings. Unarmed, under the nostalgia corner, a dark destiny awaits them. In the story tale, the child's inhuman condition is nothing more than "the great emptiness of eternity" as the annulment of individuality.

Juan Bosch, in an adverse scene, portrays the miniature of the human being of deep human sensitivity as a torn drama.

Keywords: Narrative. Phenomenology. Miniature. Solitude. Misery.

El objetivo de este trabajo pretende abordar, desde una fenomenología de la imaginación, la dialéctica ${ }^{2}$ de la miniatura en el cuento Un Niño de Juan Bosch (1997). En el relato, la aplicación del método fenomenológico se considera determinante para la concepción del símbolo en la cuentística de Juan Bosch. De ahí que, "en el eje de una filosofía que acepta la imaginación como facultad básica, puede decirse al modo schopenhaueriano: el mundo es mi representación" (Bachelard, 1975, p. 186).

Por lo demás, los estudios de G. Bachelard servirán de apoyo metodológico, y como soporte teórico los de Terry Eagleton, Una Introducción a la teoría literaria (1998), sobre todo, el apartado "Fenomenología ${ }^{3}$, hermenéutica, teoría de la recepción"; no menos, de otros autores que en buena dosis apoyen esta investigación.

\footnotetext{
${ }^{2}$ Cabe dilucidar que, en este estudio literario, la concepción dialéctica, sigue la postura platónica, "como un método de ascenso de lo sensible a lo inteligible"; pero además, la corriente de pensamiento de Hegel. En el sentido de que: "Dialéctica no sea la forma de toda la realidad, sino aquello que le permite alcanzar el carácter verdaderamente positivo". En otras palabras, escribe Hegel: "Lo lógico posee en su forma tres aspectos: a) el abstracto o intelectual; b) el dialéctico o negativo-racional; c) el especulativo positivo racional".

"La dialéctica es, en suma, lo que hace posible el despliegue y, por consiguiente, la maduración y realización de la realidad. Sólo en este sentido se puede decir que, para Hegel, la realidad es dialéctica", es decir, la "realidad realizada", en movimiento (Ferrater, 1964, pp. 444-446). "Notas".

${ }^{3}$ Esta "reducción fenomenológica" es el primer paso importante que da Husserl. Cuanto no sea "inmanente" a la conciencia debe ser rigurosamente excluido; todas las realidades deben tratarse como meros "fenómenos", en función de su apariencia en nuestra mente: estos son los únicos datos absolutos que pueden servirnos de punto de partida. De esta insistencia se deriva el nombre que Husserl dio a su sistema filosófico: fenomenología. La fenomenología es una ciencia de los fenómenos puros" (Eagleton, 1998, p.74). "Notas".
} 
Ahora bien, plantearse un problema de carácter fenomenológico con relación a las miniaturas literarias resulta de gran interés; empero, ¿̇el cuento Un Ñiño en la fenomenología de la imaginación, lo miniaturizado es susceptible de evocar una verosímil realidad?

La fenomenología de la miniatura, no solo parece obedecer a los cuentos de hadas, por ejemplo, estamos pensando en "Pulgarcito", sino también a los realistas (psicosocial), como es el caso del relato Un Niño. Aquí, el problema fenomenológico de la miniatura, parece responder al contexto sociopolítico de la República Dominicana. Así, pues, en el cuento, será necesario escudriñar ya sea el carácter objetivo, ya el subjetivo, para demostrar que en la imagen de la miniatura se esconden realidades dolorosas cargadas de lamentos humanos.

Por lo demás, en el contexto histórico-social y político del cuento, habrá de decir que, Un Niño se publica (en la primera mitad del siglo XX), durante el exilio de Juan Bosch (1938-1961). Así, pues, Un Niño, en su cabal expresión, parece ser un reflejo del fenómeno sociológico y del problema socioeconómico de la región caribeña de aquella época, en otras palabras, de la pobreza del campo 4 rural del Cibao,

Ahora bien, en el terreno que nos ocupa este estudio, a saber, Un Niño ${ }^{5}$ es otra narración que en los derroteros de la simetría canoniza la obra de Juan Bosch. El autor de La Vega, en este

\footnotetext{
${ }^{4}$ Habrá de decir que la miseria del campesino dominicano es anacrónica, ésta convive con su antiguo destino. Juan Bosch cuando describe la miseria de la República Dominicana del siglo XVII, en su libro Composición social dominicana, enfatiza que "el país vegetaba en una miseria total". Por consiguiente, en otro estudio, añade: "Aunque el infortunio histórico se cebó en él desde que comenzó la conquista y la colonización, el pueblo dominicano probó en la segunda mitad del siglo XVIII y en la novena década del siglo XIX" (Bosch, 1994, p. 200). "Notas".

Por otra parte, en el régimen de Trujillo, el mal endémico de la pobreza dominicana se concentraba en los latifundios: "El latifundio fue conservado en manos de los latifundistas que se sometieron a asociarse con Trujillo, y resultó aumentado en extensión al convertirse el propio Trujillo en el más grande latifundista del país" (Bosch, 1994, p.197). "Notas".

En la historia de la República Dominicana, Juan Bosch en su fase de historiador, puntualiza que los dominicanos, bajo el régimen de Rafael Leonidas Trujillo Molina, vivieron un triple yugo: el pueblo dominicano estaba ocupado militarmente, políticamente, sometido y, económicamente esclavizado. La gente del pueblo dominicano no gozaba de libertad para respirar el aire que recibía. Quizá bajo ese contexto de la República Dominicana, pero con el rostro metafórico, Juan Bosch esboza la atmósfera que ahoga y asfixia a los personajes. "Notas".

${ }^{5}$ Desde el primer párrafo del cuento sabemos que estamos frente a la calamidad existencial: "A poco más de media hora, cuando se deja la ciudad, la carretera empieza a jadear por unos cerros pardos, de vegetación raquítica, que
} 
relato breve, no ha de sorprender al lector con su lenguaje sencillo o aparentemente sencillo, la construcción de oraciones cortas, palabras que soslayan todo barroquismo conceptual y nos ofrecen un estilo sobrio y refinado:

Bosch es uno de los grandes maestros del cuento hispanoamericano. Su cuentística revela una depurada técnica, es preciso en cada uno de los pasos estructurales del cuento. El cuento de Bosch es profundamente humano, nos presenta al hombre virtuoso o al mezquino; a la sociedad y sus vicios, la lucha por la supervivencia o la muerte misma. Trajo a la luz el drama del campesino dominicano; la lucha de éste contra la naturaleza y su enfrentamiento con la civilización. (Piña, 1982, p. 56)

A propósito, el binarismo civilización y barbarie ${ }^{6}$ vuelve al escenario boschiano en este cuento. Así como el paisajismo ctónico y hostil que evoca el relato "La mujer". Pero más allá del inhóspito del lugar de Un Niño, está el bohío viejo y doblegado que, por sí mismo, "hace daño a la vista"; más allá, en su interior, en un rincón, sobre sacos viejos hay un negrito, bajo la imagen de la miseria que vuelca la mirada al cuento de José Luis González7, “En el fondo del caño hay un negrito", silencioso, en un rincón, "chupándose un dedo porque tiene hambre".

aparecen llenos de piedras filosas [...] Es triste el ambiente. Se ve arder el aire y sólo de hora en hora pasa algún ser vivo, una res descarnada, una mujer o un viejo (Abreu, 2003, p. 356). "Notas".

${ }^{6}$ En "Un niño", Juan Bosch nos crea una cartografía sociopolítica capaz de demostrarnos que las diferencias entre el campo y la ciudad van mucho más allá de la flora y la fauna. La flora del campo, si se trata de zonas del sur dominicano, puede ser tan descarnada y árida como la anatomía vegetal de la ciudad. Mas, si nos referimos a la fauna, en la ciudad suelen habitar ciertos tipos de animales que sobrepasan en grande la ferocidad de aquellos que habitan en el campo. Así encontramos animales tan feroces como el tránsito urbano y su secuela de polución y tensión ciudadana; igual la violencia criminal.

[...] La semiología del encuentro entre el niño y el viajero puede estirarse más allá de la mera simbología descriptiva de Juan Bosch, para conformar así una lectura sociopolítica de la relación histórica campo / ciudad.

[...]Tanta opulencia y "progreso" en la Capital y en el campo todavía hay tantos bohíos divididos en dos habitaciones, el piso de tierra, disparejo y cuarteado como en la macro miseria que engulle a aquel niño enfermo y atropellado que el viajero quiso llevarse a la ciudad para "curarlo" (Abreu, 2003, pp. 356-359). "Notas".

${ }^{7}$ Fue en Puerto Rico donde por primera vez, Bosch tiene un discípulo fuera de su país y hasta prueba en contrario, uno de los más adelantados [...]

Para cualquier lector de la narrativa boschiana, las tangencias de ésta y la narrativa de González son más que evidentes y demuestran no solamente la lectura de Bosch sino la línea que traza un discipulado. No solamente José Luis González 
A saber, en Un Niño, la anécdota es muy simple. Tras la avería de una de las ruedas de un auto donde viajan tres hombres. Uno de ellos, al escuchar una débil ${ }^{8}$ tos se asoma a un bohío casi cayéndose de viejo en aquel lugar desolado. Allí descubre a un niño solo, huérfano de madre y enfermo de fiebre, pues su padre ha salido a trabajar al campo desde muy temprano y no regresará hasta la noche. El hombre, atraído por el niño, le ofrece ayuda y desea llevarlo a la ciudad para que lo curen. El niño se niega porque allí sufrió un accidente automovilístico que lo dejó paralítico.

En Un Niño, el nudo en la garganta del personaje de segundo plano, es el mismo que provoca al lector. No menos, crujir de dientes y de estómago tras encontrarlo tembloroso y en condiciones infrahumanas. Evidentemente, el cuento refleja la desgracia de la miseria de aquel niño. La miseria, que margina y paraliza a nuestro pequeño personaje, es el eje nodal del relato. Un Niño, por su temática de extrema pobreza, converge con los cuentos: "En un bohío", "Los amos", "La mujer", "Luis Pie", y otros del autor dominicano:

En el extenso número de cuentos escritos por Juan Bosch hay varios en cuyo tema aparecen niños y niñas como personajes que encarnan sufrimiento y desamparo social y familiar. Estas son narraciones como "En un bohío", "La Nochebuena de Encarnación Mendoza", "La desgracia" y "La mujer", que denuncian situaciones difíciles, complejas. Casi todas éstas, a veces carentes de atención o afecto suficiente $y$, sobre todo, son las primeras víctimas de la desigualdad y abandono social que padecen sus padres. Bajo el marco de esta ficción están ausentes la sonrisa, los juegos y travesuras tan característicos de esta etapa de vida. Esta situación se repite en el cuento de estilo realista Un Niño. (Emeterio, 2012, p. 163)

En Juan Bosch, la desmedida sensibilidad social y humana, innegablemente, es como la de su personaje. Ese hombre de ceño áspero que de pronto se ve encantado por la dulzura y la sonrisa de aquel niño enfermo hecho casi huesos, "el negrito Melodía", pero no de José Luis González, sino de Juan Bosch. En el hombre, en extraña expresión, la dureza de su rostro ha sido suavizada. El niño lo

siguió a Bosch en Puerto Rico, sino que otros escritores como Abelardo Díaz Alfaro hicieron de las técnicas y de la corriente realista del cuento boschiano su línea poética (Fornerín, 2001, p. 448). "Notas".

${ }^{8}$ La voz, ser frágil y efímero, puede dar testimonio de las fuertes realidades (Bachelard, 1975, p.218). "Notas". 
ha conmocionado, petrificado en hondo dolor. Mientras que la indiferencia de uno de los viajeros, descansa en la conquista del imperialismo yanqui: "fumaba un cigarrillo americano" (Bosch, 1997, p.50).

A juzgar por la estructura narrativa, Un Niño es un cuento más de descripción que de narración ${ }^{10}$. Es una imagen pictórica de la miniatura. En el relato, llama, poderosamente, la atención que ningún personaje tiene nombre, todos son referidos por sus rasgos físicos. Viven en la anonimia.

Por lo demás, Juan Bosch, con dimensión artística de quien sabe contar historias, nos presenta, en una serie de contrastes y paralelismos, el tejido narrativo de este relato cargado de dramatismo. De suyo que, Rodrigo Carazo se refiera al autor como jel Dostoievski dominicano!

En la diégesis, la unidad de acción inicia, precisamente, con el paso estridente de un auto: "Pasó un automóvil con horrible estrépito y levantando nubes de polvo11" (Bosch, 1997, p. 50). En la secuencia de acción: "el conductor del averiado vehículo sudaba y se mordía los labios" (Bosch, 1997, p. 50). En el cuento, la rueda averiada del auto de los viajeros, ocurre, justamente, frente al bohío donde habita el niño. Juan Bosch, con este extraordinario recurso narrativo, marca una precisión de acciones en el presente continuo y, a la vez, evoca la imagen del golpe recibido del niño por el auto, la desgracia (la doble) que lo deja inmovilizado. A título de ejemplo:

Se oían los golpes que daba el conductor afuera.

-¿Qué pasó?- preguntó la criatura.

\footnotetext{
${ }^{9}$ [...] la Tabacalera, única fábrica de cigarrillos del país, que era propiedad de extranjeros y que acabó siendo propiedad de Trujillo. En el preciso momento en que Trujillo comenzaba a tener acciones de la Tabacalera empezó a instalarse en el país la Reynold Tobacco, una poderosa firma norteamericana dedicada a fabricar cigarrillos. Trujillo actuó en ese momento con decisión y celeridad y forzó a la Reynold a cerrar su fábrica. Así, el dictador retuvo el monopolio dominicano de cigarrillos hasta el día de su muerte, aunque parece que las acciones estaban a nombre de su esposa, la señora María Martínez (Bosch, 1995, p. 393). "Notas".

${ }^{10}$ El contrapunto dramático, la tensión narrativa, toma mayor fuerza con los diálogos entre los dos personajes principales, y con la descripción del ambiente al interior del bohío donde vive el niño (Emeterio, 2012, p.164). "Notas".

${ }^{11}$ Disolución del mineral, es decir, estado de máxima destrucción, aún perceptible, de la forma más baja de la realidad a la metrología humana. Por tanto, el polvo, como la ceniza (aunque ésta concierne al fuego y el polvo a la tierra), tiene un sentido negativo relacionado con la muerte (Cirlot, 1969, p. 375). "Notas".
} 
-Un goma ${ }^{12}$ que se reventó, pero están arreglándola. Así que hay que arreglarte a ti también. Hay que curarte. ¿Qué te parece si te llevo a la Capital para que te sanes? ¿Dónde está tu papá? ¿Lejos?

-Unjú...Viene de noche y se va amaneciendo [...]

Estaba levantando al enfermito y le sorprendió sentirlo tan liviano, como si fuera un muñeco de paja. El niño le miró con ojos de terror, que se abrían más, mucho más de lo posible. Entonces cayó al suelo el saco de pita que lo cubría. El hombre se heló, materialmente se heló. Iba a decir algo y se le hizo un nudo en la garganta [...]

-¿`Y cómo fue eso? -atinó a preguntar.

-Allá- explicó la criatura mientras señalaba con un gesto hacia la distante ciudad-. Allá... un auto.

Justamente en ese momento sonó la bocina. Alguien llamaba al hombre y él puso al niño de nuevo en el suelo, sobre los sacos que servían de cama, y salió como un autómata aturdido. (Bosch, 1997, pp. 52-53)

Ahora bien, para Bachelard (1975), en la fenomenología de la imaginación, el espacio poético de la choza, bajo la perspectiva de la mirada que muchas veces resulta engañosa a la vista, el soñador queda suspendido para anclarse en ese espacio minúsculo, rodeado de soledad. De suyo que:

Las aldeas perdidas en el horizonte son entonces patrias de la mirada. Lo lejano no dispersa nada. Al contrario, reúne en una miniatura un país donde nos gustaría vivir. En las miniaturas de lo lejano vienen a "componerse" las cosas dispares. Se ofrecen entonces a nuestra

\footnotetext{
${ }^{12}$ Una de las formas elementales del simbolismo de la rueda consiste en la interpretación del sol como rueda, y de las ruedas ornamentales como emblemas solares. A este propósito, Krappe señala que uno de los conceptos más extendidos de la Antigüedad es la idea del sol como rueda [...] La rueda del fuego simboliza en síntesis, por consiguiente, las fuerzas cósmicas en movimiento y el tiempo como proceso (rotación de todo ciclo) [...] También la esvástica, que es un signo intermedio entre la cruz y la rueda, es considerada por unos como signo solar y por otros como signo del polo. Guénon se inclina por esta última hipótesis. Pero sea como fuere, a lo que en última instancia, se alude es a la descomposición del orden del mundo en dos estructuras esenciales y distintas: el movimiento rotatorio y la inmovilidad; la circunferencia de la rueda y su centro, imagen del motor inmóvil "aristotélico". Este tema es obsesionante para la mentalidad mítica, y aparece en la alquimia bajo la contraposición de lo volátil (en movimiento y por lo tanto lo transitorio) y fijo (Cirlot, 1969, p. 395). "Notas".

Evidentemente, el último, es decir, la estructura inmóvil se vincula con el cuento “Un Niño”.
} 
posesión, negando la distancia que las ha creado. ¡Poseemos de lejos, y con cuánta tranquilidad! (p. 209)

Y, en Un Niño: "el bohío estaba justamente en el más alto de aquellos chatos cerros [...] Uno de ellos corrió la vista hacia las remotas manchas ${ }^{13}$ verdes que se esparcían por los declives de los cerros" (Bosch, 1997, p. 49). En el cuento, curiosamente, el bohío es una aldea perdida en lo inhóspito de la geografía cibaeña.

A saber, en la fenomenología de la imagen miniaturizada, el bohío no es otra cosa que la inmensa soledad del niño enfermo. Cabe añadir que su madre ha muerto desde que él era muy pequeño. Y "iqué lección de soledad!" para aquellos hombres, los viajeros quienes se han quedado varados por un instante frente aquel bohío y sienten odiar la soledad de ese lugar. A renglón seguido se lee: “¿Crees que alguien pueda no odiar esto, tan solo, tan abatido, sin alegría, sin música, sin mujeres? (Bosch, 1997, p.50) iQué paradoja! El lugar llamado Matahambre no ocupa la geografía en la que los hombres deseen vivir, más bien lo aborrecen, mientras que el niño siente lo mismo por la ciudad. Pero pongamos dos referencias de esto:

Los viajeros no pueden adaptarse a la soledad del campo al igual que el niño no puede adaptarse a la vida de la ciudad. La imposibilidad de establecer una diferenciación entre lo bárbaro/lo civilizado, por la ambigüedad que supone, hay que entenderlo, desde la mirada de Bosch, dentro de un código de incomunicación [...]. (Pichardo, 2009, p. 321)

Lo interesante aquí es el contraste ciudad (modernidad, civilización, progreso) versus campo (desolación atraso y abandono), presentado en esta antología únicamente en este cuento. Esa exposición de contrastes recuerda que la modernidad crea una visión engañosa de la realidad al querer presentar el progreso como algo global y uniforme mientras se oculta la

\footnotetext{
${ }^{13}[\ldots]$ Tienen relación con el de las nubes, en cuanto ambas generan figuras ilusorias que pueden ser identificados por procesos de interpretación análogos [...] con frecuencia las manchas están asociadas con el paso del tiempo, aluden así a las ideas del transcurso y de la muerte. De otro lado, las manchas, decoloraciones e imperfecciones de todo género pueden adscribirse al simbolismo de lo anormal pues, según los alquimistas, esas "enfermedades" de los objetos o materias constituyen, la auténtica "primera materia", la base para la preparación del oro filosófico (evolución espiritual) (Cirlot, 1969, p. 314). "Notas".
} 
cara de la pobreza y la miseria. Al final de esta historia aparece como punto de vista del narrador una reflexión: la civilización, además de ser cine, periódicos, luz, autos...también es dolor. (Emeterio, 2012, p. 165)

En la dialéctica de lo miniaturizado, en Un Niño, la imagen del bohío que se halla en lo más alto de los cerros, aquí encontraría, quizá, su mejor expresión, pues según Bachelard (1975): “en las miniaturas de lo lejano vienen a componerse las cosas dispares" (p.209) (Ibídem). Pero “¿cómo resistía esa criatura la vida?", quizá esta pregunta retórica nos lleve a otras. Sabemos que a pesar de las circunstancias adversas en las que vive, él prefiere la triste soledad de ese lugar que la estridente ciudad.

Por otra parte, para el llamado "filósofo de la imaginación", Bachelard (1975) todo rincón de una casa de un cuarto o el espacio reducido donde nos gusta acurrucarnos, agazaparnos sobre nosotros mismos es, en la dialéctica de la soledad, el origen de un cuarto, de una casa. Así, pues, en muchos aspectos el rincón "vivido" se niega a la vida. El rincón es una negación del universo. En el rincón no se habla consigo mismo, sino con el silencio de voces, el silencio de los pensamientos ( $p$. 171). Al respecto, sirva de ejemplo esta imagen literaria:

La choza estaba dividida en dos habitaciones. El piso de tierra, disparejo y cuarteado, daba la impresión de la miseria aguda. Había suciedad, papeles, telarañas ${ }^{14}$ y una mugrosa mesa en un rincón, con un viejo sombrero de fibras encima. El lugar era claro a pedazos [...] En la

\footnotetext{
${ }^{14}$ También en el cuento "Un Niño" "la meditabunda araña "vive poderosa y feliz" en la vida humana (Bachelard, 1975, p. 175). "Notas".

Aparte de su relación con la araña, su simbolismo es el mismo que el del tejido en general. Por su forma espiral presenta también la idea de creación y desenvolvimiento, de rueda y de centro. Pero en éste espera la destrucción y la agresión. La telaraña con la araña en medio simboliza, pues, lo mismo que la Medusa Gorgona representada en el centro de algunos mosaicos: es el torbellino devorador. Probablemente un símbolo de intuición negativa del universo, que ve el mal no solo en la periferia de la rueda de las transformaciones, sino en su propio centro, es decir, en su origen. Noción gnóstica (Cirlot, 1969, p. 122). "Notas".
} 
única portezuela de la otra habitación se detuvo y vio un bulto en un rincón. Sobre sacos ${ }^{15}$ viejos, cubierto hasta los hombros, un niño temblaba. Era negro, con la piel fina, los dientes blancos, los ojos grandes, y su escasa carne dejaba adivinar los huesos. (Bosch, 1997, p.51)

De acuerdo con Bachelard (1975) en la dialéctica de la soledad encerrada (y que es, precisamente, la que vive nuestro pequeño personaje), ésta negaría el mundo de otro modo. No tendría para dominarlo una imagen concreta. Según el fenomenólogo, muchas veces el soñador se convierte en el ser de su imagen, es decir, éste absorbe todo el espacio de su imagen miniaturizada hasta llegar a fundirse en una miniatura de ser:

Desde lo alto de su torre, el filósofo de la dominación miniaturiza el universo. Todo es pequeño porque él está en lo alto. Es alto, por tanto es grande. La altura de su albergue es una prueba de su propia grandeza". (p. 210)

En el cuento, recordemos que el niño se niega a la vida de la ciudad, a lo "civilizado". El narrador omnisciente nos dice: "Pero los niños no saben lo que quieren" (Bosch, 1997, p. 53). Evidentemente, él no tiene una imagen concreta del mundo, antes bien, en la dialéctica de los contrarios: "oú les enfants regardent grand [donde los niños ven grande] (Bachelard, 1975, p. 191). Ipso facto lo domina "el reino de la ingenuidad" y él quizá no alcanza a ver la puerta estrecha de su pobre bohío que se abre al mundo: "el detalle de una cosa puede ser el signo de un mundo nuevo, de un mundo, que como todos los mundos, contiene los atributos de la grandeza" (Bachelard, 1975, p. 192). No obstante, la altura de su espacio (de su choza) es la grandeza de su alma, es la altura en la dialéctica de lo dentro y de lo de fuera, y por eso el niño con su cándida dulzura y su sonrisa melódica, ha de encantar a ese hombre de rostro severo y triste: "[...] La miniatura adopta las dimensiones del universo. Lo grande está una vez más contenido en lo pequeño [...] la miniatura es uno de los albergues de la grandeza" (Bachelard, 1975, pp. 192-194).

\footnotetext{
${ }^{15}$ Sacos, cordeles y fibras tejidas: Monopolio de Trujillo que va desde la siembra de las plantas fibrosas hasta la manufactura y venta de los artículos que cubren todo el mercado nacional. La ley castiga severamente el uso, por más de una vez, de los sacos fabricados por el dictador (Bosch, 1998, p. 73). "Notas".
} 
En el rincón, ese rincón de sacos viejos donde tiembla el niño, es su pobre refugio que, según Bachelard (1975), “nos asegura su primer valor del ser: la inmovilidad [...] La conciencia de estar en paz en su rincón", esa inmovilidad donde las sombras se convierten, en la dialéctica de la imagen, en muros, un mueble, en una barrera [...] En síntesis, el espacio de la inmovilidad se convierte en el espacio del ser: Je suis l'espace oú je suis [Yo soy el espacio donde estoy] (p. 172).

En el cuento, el niño en el espacio del ser, en el arquetipo de la miniatura, es visto "como si fuera un muñeco de paja" (Bosch, 1997, p. 53), un bulto, una cosa, un saco más. Para colmo de males, el niño no sabe leer ni escribir, menos tiene idea que significan esas palabras. Está reducido a la espera del oscuro destino: "Pensó en la noche: llegaría con sus sombras, y ese niño enfermo, con fiebre, tal vez señalado por la muerte, estaría ahí solo, esperando al padre, sin hablar palabra, sin oír música, sin ver gentes" (Bosch, 1997, p. 52).

En Un Niño, la choza, ese párvulo lugar descrito a pedazos, donde el sol entra por los agujeros del techo, donde "irradia la inmovilidad". Ese nido de polvo donde el niño está literalmente inmovilizado, olvidado en la nostalgia del rincón tal si fuera un muñeco de paja; ese estremecimiento del hombre extraño ante la condición inerme y deshumana del niño, no es más que, "el gran vacío de la eternidad" Más aún, nosotros, lectores, "lectores del rincón" somos albergue del olvido y de la soledad", añade Bachelard (1975, pp. 176-177).

Empero, en Un Niño, “¿cómo decir mejor que el rincón es el casillero del ser?” En la dialéctica de la soledad encerrada del niño, la fenomenología de la imagen miniaturizada, no solo niega al mundo, sino que anula la individuación.

\section{Conclusiones}

El cuadro descriptivo de la miniatura de Un Niño esboza la redondez literaria de este maravilloso cuento, pero también doloroso. Juan Bosch sabe dar el salto asesino y herir al lector más adusto.

En Juan Bosch resulta una constante, en su narrativa, la presencia de los niños, cuyos rasgos más comunes de estos seres desdichados que, bajo el filo de la pobreza que rasga e indigna, 
asoman enfermos de fiebre, enfermos, flacos, huérfanos, hambrientos, analfabetas e inermes; sobrada condición inhumana y de la injusticia social de la realidad de América Latina.

Pero en Un Niño como en otros cuentos de Bosch, la ignominia social, la minimización de estos pobres seres llevan, literariamente, en el rostro, la insignia oficial dominicana trujillista, y si nos quedara algún resquicio de la duda, léase lo siguiente:

En 1930, Santo Domingo era la tierra ideal para un empresario sin conciencia pero con energía y capacidad, que empleara la energía sólo en aumentar sus caudales sin tomaren en cuenta el valor de la vida, la dignidad humana, el derecho de los dominicanos a la libertad de bienestar. (Bosch, 1998, pp. 26-27)

Un dominicano que tenga coraje para luchar por su independencia tendrá que desafiar el hambre, la suya y la de sus familiares; y si la desafía y se niega a someterse al amo de la empresa nacional, tendrá que enfrentar las leyes de gobierno, instrumento de la empresa, y esas leyes son hechas y rehechas cada día, a la medida de las necesidades de la empresa, para que nadie pueda rebelarse contra el amo. (Bosch, 1998, pp.34-35).

\section{Referencias}

Abreu, D. (2003). La obra narrativa de Juan Bosch: herencia estética y filosófica de varias generaciones. En Miguel Collado (Ed.). Juan Bosch, Maestro de la narrativa latinoamericana. Santo Domingo, República Dominicana: CEDIBIL.Pp.347-359.

Bachelard, G. (1975). La poética del espacio. (2a. ed.). (Ernestina de Champourcin, Trad.). Ciudad de México, México: Fondo de Cultura Económica.

Bosch, J. (1994). Trujillo Causas de una tiranía sin ejemplo. (6a.ed.) Santo Domingo, República Dominicana: Alfa y Omega.

Bosch, J. (1995). Composición Social Dominicana. (18a. ed.) Santo Domingo, República Dominicana: Alfa y Omega.

Bosch, J. (1997). Más Cuentos Escritos en el Exilio. (16a. ed.) Santo Domingo, República Dominicana: Alfa y Omega. 
Bosch, J. (1998). La fortuna de Trujillo. (5a.ed.) Santo Domingo, República Dominicana: Alfa y Omega.

Cirlot, J. E. (1969). Diccionario de símbolos. (2ª.ed.) Barcelona, España: Labor.

Emeterio, R. M. (2012). Cuentos inolvidables de Juan Bosch. República Dominicana: Santillana.

Ferrater, M. J. (1964). Diccionario de Filosofía. Recuperado de https://www.lacanterafreudiana.com.ar/Ferrater\%20Mora\%20-

\%20Dicc\%20de\%20Filosofia\%20D.PDF

Fornerín, M. A. (Octubre-Diciembre de 2001). José Luis González: el alumno más avanzado de Juan Bosch. La torre. Revista de la Universidad de Puerto Rico. VI(22). 447-455.

Pichardo, N. C. (2009). Juan Bosch y la Canonización de la Narrativa Dominicana. Santo Domingo, República Dominicana: FUNGLODE.

Piña, C. G. (1982). Doce en la literatura dominicana. Santiago, República Dominicana: Universidad Católica Madre y Maestra.

Terry, E. (1998). Una Introducción a la teoría literaria. Ciudad de México, México: Fondo de Cultura Económica 